\title{
Pengaruh E-SPT, Sanksi, Sosialisasi, Pengetahuan Perpajakan, dan Moralitas pada Kepatuhan Wajib Pajak
}

\author{
Ni Luh Putu Dian Patni Lhoka ${ }^{1}$ \\ Fakultas Ekonomi dan Bisnis \\ Universitas Udayana, Indonesia \\ Email: dianpatni10@gmail.com
}

\author{
I Made Sukartha ${ }^{2}$ \\ Fakultas Ekonomi dan Bisnis \\ Universitas Udayana, Indonesia
}

\begin{abstract}
ABSTRAK
Pajak merupakan sumber penerimaan Negara terbesar di Indonesia. Kepatuhan menjadi faktor penting dalam meningkatan penerimaan pajak karena kepatuhan perpajakan adalah sikaptaat, patuh, tunduk, dan melaksanakan ketentuan tentang perpajakan. Penelitian ini dilakukan di KPP Pratama Tabanandengan menggunakan sampel sebanyak 390 wajib pajak orang pribadi non karyawan yang ditentukan menggunakan metode nonprobability sampling dengan teknik accidental sampling. Metode analisis data yang digunakan pada penelitian ini adalah analisis regresi linier berganda. Hasil penelitian menemukan bahwa, e-SPT, sanksi, sosialisasi, pengetahuan perpajakan, dan moralitas berpengaruh positif pada kepatuhan wajib pajak orang pribadi non karyawan yang terdaftar di KPP Pratama Tabanan.

Kata Kunci: E-SPT; Sanksi; Sosialisasi; Pengetahuan Perpajakan; Moralitas; Kepatuhan Wajib Pajak.

\section{The Effect of E-SPT, Sanctions, Socialization, Taxation Knowledge, and Morality on Taxpayer Compliance}

\section{ABSTRACT}

Taxes are the largest source of state revenue in Indonesia. Compliance is an important factor in increasing tax revenue because tax compliance is the attitude of compliance, compliance, submission, and application of tax provisions. This research was conducted at KPP Pratama Tabanan using a sample of 390 non-employee taxpayers who were determined using the nonprobability sampling method with accidental sampling technique. The data analysis method used in this study is multiple linear regression analysis. The results found that, e-SPT, sanctions, socialization, tax knowledge, and morality had a positive effect on the tax compliance of non-employee individuals registered at the KPP Pratama Tabanan.

Keywords: $\quad$ E-SPT; Sanctions; Socialization; Taxation Knowledge; Morality; Taxpayer Compliance.

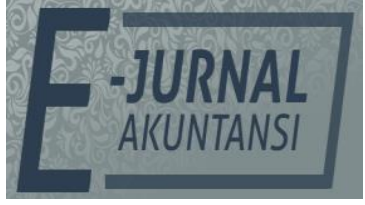

E-JA

e-Jurnal Akuntansi e-ISSN 2302-8556

Vol. 30 No. 7

Denpasar, Juli 2020

Hal.1699-1711

Artikel Masuk: 27 Januari 2020

Tanggal Diterima: 17 Maret 2020

The Article is Available in: https://ojs.unud.ac.id/index.php/Akuntansi/index 


\section{PENDAHULUAN}

Penerimaan terbesar Negara bersumber dari penerimaan pajak, sehingga pajak diandalkan untuk pembangunan dan pengeluaran pemerintahan (M. Handayani \& Noviari, 2016). Namun, pemungutan pajak sampai saat ini belum dilakukan secara optimal (Sondakh, 2017). Kepatuhan wajib pajak memiliki peran penting dalam meningkatkan penerimaan negara. Kepatuhan wajib pajak ialah keadaan wajib pajak yang sudah memenuhi semua kewajiban perpajakannya serta menerima hak sebagai wajib pajak sesuai dengan peraturan yang berlaku (Marjan, 2014). Kepatuhan wajib pajak yang ada di Indonesia saat ini masih perlu untuk diperbaiki karena sering menjadi salah satu kendala utama yang dapat melemahkan administrasi perpajakan dan menghambat penerimaan negara, terutama penerimaan di sektor perpajakan (Heenkenda, 2016). Penelitian Mahangila (2017) menyebutkan, dibandingkan negara-negara lain, tax ratio di Indonesia masih harus terus ditingkatkan agar dapat mengejar ketertinggalan. Tax ratio Indonesia lebih kecil dibandingkan dengan tax ratio di negara-negara ASEAN dan Organisation on Economic Cooperation and Development. Pada tahun 2018 tax ratio Thailand 17,6 persen, Filipina 17,5 persen, Singapura 14,1 persen, Malaysia 13,6 persen, dan tax ratio Indonesia yaitu 11,5 persen (Direktorat Jenderal Pajak, 2019).

Faktor ekonomi, sosial, psikologis, dan demografis dapat mempengaruhi perilaku kepatuhan pembayar pajak (Redaae \& Sekhon, 2016). Penelitian Chirkos (2015), Yulitasari \& Suprasto (2017), Adnyana \& Jati (2018), Setyani (2018), dan Naufal \& Setiawan (2018) menyatakan bahwa kesadaran wajib pajak, sanksi, kualitas pelayanan fiskus, tax amnesty, motivasi wajib pajak, pengetahuan perpajakan, dan e-filling merupakan faktor yang mempengaruhi kepatuhan wajib pajak. Hasil penelitian Fernando \& Arisman (2017) serta Markumah, et al. (2019) menyatakan sanksi, reformasi perpajakan, dan pengetahuan perpajakan tidak berpengaruh pada kepatuhan wajib pajak. Namun, secara umum kepatuhan wajib pajak dapat dipengaruhi oleh faktor internal dan faktor eksternal. Hal tersebut mendukung teori atribusi, yang menyatakan bahwa perilaku seseorang dapat dipengaruhi oleh adanya dorongan dari internal ataupun eksternal. Penelitian ini dilakukan di KPP Pratama Tabanan karena tingkat kepatuhan wajib pajak orang pribadi di KPP tersebut mengalami fluktuasi beberapa tahun terakhir. Selain itu, rasio tingkat kepatuhan wajib pajak orang pribadi non karyawan di KPP Pratama Tabanan pada tahun 2018 lebih rendah dibandingkan dengan kepatuhan wajib pajak orang pribadi karyawan yaitu 52 persen. Penelitian dilakukan karena adanya perbedaan hasil dari penelitian sebelumnya. Tujuan penelitian ini adalah untuk memberikan bukti empiris pengaruh e-SPT, sanksi, sosialisasi, pengetahuan perpajakan, dan moralitas pada kepatuhan wajib pajak orang pribadi non karyawan di KPP Pratama Tabanan. Hasil penelitian ini memberikan bukti empiris dan mendukung teori atribusi bahwa kepatuhan wajib pajak orang pribadi dapat dipengaruhi oleh faktor internal seperti pengetahuan perpajakan dan moralitas serta faktor eksternal seperti e-SPT, sanksi, dan sosialisasi. Selain itu, penelitian ini dapat memberikan informasi, dan referensi sebagai pertimbangan untuk wajib pajak dalam meningkatkan kepatuhan membayar pajak. Bagi KPP (Kantor Pelayanan Pajak) penelitian ini dapat digunakan sebagai 
pertimbangan dalam mengambil kebijakan untuk meningkatkan kepatuhan wajib pajak dalam membayar pajak.

Heider (1958) mengemukakan bahwa teori atribusi dapat menjelaskan tentang perilaku seseorang serta mengkaji bagaimana proses seseorang dalam menginterpretasi sebuah peristiwa ataupun penyebab dari suatu perilaku. Teori atribusi menyatakan bahwa apabila individu mengamati perilaku seseorang, mereka menentukan apakah itu ditimbulkan secara internal atau eksternal (Robbins \& Judge, 2013). Perilaku yang disebabkan oleh faktor internal adalah perilaku yang berada di bawah kendali individu itu sendiri (internal forces) seperti kepribadian, kesadaran, dan kemampuan. Perilaku yang disebabkan oleh faktor eksternal adalah perilaku yang dipengaruhi dari luar individu (external forces) seperti pengaruh orang lain yang menyebabkan individu akan terpaksa berperilaku karena situasi atau keadaan. Berdasarkan teori atribusi, e-SPT merupakan faktor eksternal dimana prilaku wajib pajak dalam hal ini kepatuhan wajib pajak dapat didorong oleh adanya faktor eksternal. Elektronik SPT (e-SPT) adalah sebuah aplikasi dari Direktorat Jenderal Pajak Kementerian Keuangan yang dapat digunakan wajib pajak untuk memudahkan dalam menyampaikan SPT. Parwati, et al, (2017) menyatakan bahwa dengan adanya teknologi yang canggih melalui layanan online, Direktorat Jenderal Pajak (DJP) Indonesia dapat memfasilitasi layanan laporan elektronik yang efektif. Penelitian yang dilakukan oleh Pratami, et al. (2017), menunjukkan bahwa e-SPT berpengaruh positif pada kepatuhan wajib pajak sehingga semakin tinggi penggunakan e-SPT maka kepatuhan wajib pajak semakin tinggi. Hipotesis yang dapat dirumuskan berdasarkan uraian tersebut dan hasil penelitian sebelumnya adalah

$\mathrm{H}_{1}$ : E-SPT berpengaruh positif pada kepatuhan wajib pajak.

Sanksi perpajakan termasuk faktor eksternal dalam teori atribusi. Sanksi perpajakan dibuat untuk meningkatkan kedisiplinan wajib pajak dalam mentaati peraturan pajak sehingga kepatuhan wajib pajak akan meningkat. Pranata \& Puspa (2015) menyatakan bahwa sanksi perpajakan adalah hukuman pada wajib pajak yang melanggar ketentuan perpajakan agar wajib pajak lebih menaati ketentuan undang-undang yang berlaku. Sanksi perpajakan membuat biaya yang dikeluarkan lebih besar dibandingkan pada saat patuh dalam melaksanakan kewajiban perpajakannya (Hartana \& Merkusiwati 2018). Priambodo (2018) serta Kusumafanto \& Achyani (2018) dalam penelitiannya menemukan adanya pengaruh positif dari sanksi pada kepatuhan wajib pajak, semakin tegas sanksi yang diberikan maka wajib pajak akan taat dengan peraturan dan dapat meningkatkan kepatuhan wajib pajak. Berdasarkan uraian tersebut dan hasil penelitian sebelumnya dapat dirumuskan hipotesis:

$\mathrm{H}_{2}$ : Sanksi pajak berpengaruh positif pada kepatuhan wajib pajak.

Faktor internal dan faktor eksternal dapat memengaruhi tindakan ataupun perilaku yang dilakukan oleh individu, hal ini dijelaskan dalam teori atribusi. Berdasarkan teori tersebut sosialisasi perpajakan merupakan faktor ekternal yang dapat mepengaruhi kepatuhan wajib pajak. Upaya untuk memberikan informasi dan pembinaan kepada masyarakat mengenai segala sesuatu yang berhubungan dengan perpajakan dan perundang-undangan dapat dilakukan dengan sosialisasi. (Savitri \& Musfialdy, 2016) menyatakan sosialisasi dapat memberikan pemahaman terkait perpajakan dan aturannya sehingga dapat 
memotivasi wajib pajak untuk meningkatkan kepatuhan. Penelitian Naufal \& Setiawan (2018), Fernando \& Arisman (2017), dan Andreas \& Savitri (2015) menyatakan sosilisasi berpengaruh positif pada kepatuhan wajib pajak. Berdasarkan uraian tersebut, hipotesis yang dapat dirumuskan adalah:

$\mathrm{H}_{3}$ : Sosialisasi berpengaruh positif pada kepatuhan wajib pajak.

Pengetahuan perpajakan dalam kaitannya dengan teori atribusi merupakan faktor internal dari wajib pajak. Pengetahuan merupakan sesuatu yang diketahui yang didapatkan melalui proses pembelajaran (Damajanti \& Karim, 2017). Pengetahuan perpajakan ialah pemahaman dasar bagi wajib pajak mengenai hukum, undang-undang, dan tata cara perpajakan yang benar (Wijayanti \& Sukartha, 2018). Hasil penelitian Wardani \& Wati (2018) serta Kesumasari \& Suardana (2018) menyatakan pengetahuan perpajakan berpengaruh positif terhadap kepatuhan wajib pajak. Handayani \& Damayanti, (2018) serta Manual \& Xin, (2016) menyatakan semakin meningkatnya pengetahuan mengenai perpajakan dapat mempengaruhi tingkat kepatuhan wajib pajak. Hal tersebut mengindikasikan bahwa apabila wajib pajak memiliki pengetahuan mengenai perpajakan, maka mereka akan melaksanakan semua kewajiban pajak mereka sesuai dengan yang ditetapkan peraturan, sehingga kepatuhan dalam membayar pajak akan meningkat. Hipotesis yang dapat dirumuskan berdasarkan uraian tersebut adalah

$\mathrm{H}_{4}$ : Pengetahuan perpajakan berpengaruh positif pada kepatuhan wajib pajak.

Perilaku seseorang dapat disebabkan dari faktor internal atau dari faktor eksternal. Berdasarkan teori atribusi, moralitas merupakan faktor internal yang meliputi etika, prinsip hidup, dan perasaan bersalah apabila tidak melaksanakan kewajiban moral yang dimiliki setiap orang. Wanzel, et al. (2002) menyebutkan wajib pajak cenderung berperilaku jujur dan taat terhadap aturan yang telah diberikan jika wajib pajak memiliki kewajiban moral yang baik. Penelitian Yulitasari \& Suprasto (2017) serta Pratiwi \& Merkusiwati (2019) menyatakan moralitas memiliki pengaruh positif pada kepatuhan wajib pajak. Wajib pajak yang memiliki tangung jawab moral yang besar, maka tingkat pemenuhan kewajiban pajaknya tinggi. Tanggung jawab moral akan mendorong wajib pajak untuk patuh dalam melaporkan pajaknya. Berdasarkan uraian tersebut dan hasil penelitian sebelumnya dapat dirumuskan hipotesis sebagi berikut $\mathrm{H}_{5}$ : Moralitas berpengaruh positif pada kepatuhan wajib pajak.

\section{METODE PENELITIAN}

Penelitian ini dilakukan di KPP Pratama Tabanan yang beralamat di Jalan Gatot Subroto Sanggulan, Tabanan, Bali. Objek penelitiannya yaitu kepatuhan wajib pajak $(Y)$ yang dijelaskan oleh pengaruh e-SPT $\left(X_{1}\right)$, sanksi $\left(X_{2}\right)$, sosialisasi $\left(X_{3}\right)$, pengetahuan perpajakan $\left(\mathrm{X}_{4}\right)$, dan moralitas $\left(\mathrm{X}_{5}\right)$.

Data yang digunakan adalah data kuantitatif yaitu hasil dari kuesioner yang diukur dengan menggunakan skala likert. Sumber data berupa data primer yaitu hasil kuesioner yang telah diisi oleh responden yaitu wajib pajak orang pribadi non karyawan yang efektif di KPP Pratama Tabanan dan data sekunder yang berupa data jumlah wajib pajak orang pribadi yang terdaftar di KPP Pratama Tabanan. 
Variabel kepatuhan wajib pajak diukur menggunakan kuesioner yang dikembangkan oleh Dewi (2019), terdiri dari 7 pernyataan dengan indikator dari kepatuhan wajib pajak adalah a. terdaftar sebagai wajib pajak; b. ketepatan waktu pelaporan; dan c. perhitungan pajak. E-SPT diukur dengan menggunakan kuesioner yang dikembangkan oleh Adnyana (2018) yang terdiri dari 10 pernyataan, indikator dari variabel e-SPT adalah a. kemudahan pengisian e-spt; b. efisiensi dan efektivitas; dan c. keamanan sistem e-SPT. Variabel sanksi diukur menggunakan kuesioner yang dikembangkan oleh Purwadi (2019) yang terdiri dari 5 pernyataan, indikator dari sanksi perpajakan adalah a. sanksi bersifat tegas; dan b. sanksi sebagai pencegah pelanggaran. Pengukuran variabel sosialisasi menggunakan kuesioner dari Kusumayanthi \& Suprasto (2019) terdiri dari 6 pernyataan, indikator sosialisasi adalah a.media yang digunakan; dan b.manfaat sosialisasi. Pengetahuan perpajakan dalam penelitian ini diukur dengan kuesioner yang dikembangkan oleh Juliantara (2017) yang terdiri dari 5 pernyataan, indikator dari variabel pengetahuan perpajakan adalah a. pengetahuan mengenai batas waktu pembayaran dan pelaporan; dan $b$. pengetahuan mengenai ketentuan umum dan tata cara perpajakan. Moralitas pada penelitian ini diukur menggunakan kuesioner yang dikembangkan Fauziah (2016) yang terdiri dari 4 pernyataan, yaitu a. melanggar etika yang ada; dan b. perasaan bersalah jika wajib pajak tidak memenuhi kewajibannya.

Penelitian ini menggunakan teknik accidental sampling yang merupakan teknik penentuan sampel berdasarkan kebetulan. Populasi dalam penelitian ini adalah wajib pajak orang pribadi non karyawan yang efektif di KPP Pratama Tabanan yang berjumlah 13.956. Jumlah sampel ditentukan dengan menggunakan rumus Slovin, sehingga diperoleh sampel sebanyak 390.

Kuesioner dalam penelitian ini ditujukan pada wajib pajak orang pribadi non karyawan yang efektif di KPP Pratama Tabanan. Hasil dari kuesioner akan diukur dengan menggunakan skala likert 5 poin. Jawaban yang didapat akan dibuat skor yaitu: (1) sangat tidak setuju, (2) tidak setuju, (3) netral, (4) setuju, dan (5) sangat setuju. Hasil analisis dinyatakan dalam bentuk persamaan regresi linear berganda sebagi berikut (Sugiyono, 2016).

$Y=\alpha+\beta_{1} X_{1}+\beta_{2} X_{2}+\beta_{3} X_{3}+\beta_{4} X_{4+}$

\section{HASIL DAN PEMBAHASAN}

Data dalam penelitian ini berasal dari penyebaran kuesioner pada wajib pajak orang pribadi non karyawan yang efektif di KPP Pratama Tabanan. Distibusi kuesioner dapat dilihat pada Tabel 1.

Tabel 1. Distribusi Kuuesioner

\begin{tabular}{lll}
\hline Item & Jumlah & Persentase \\
\hline Kuesioner yang dibagikan & 390 & $100 \%$ \\
Kuesioner yang tidak diisi & 0 & \\
Kuesioner yang tidak diisii dengan lengkap & 0 & \\
Kuesioner yang dapat diolah & 390 & $100 \%$ \\
Tingkat Pengembalian Kuesioner (respon rate)) & 390 & $100 \%$ \\
Kuesioner yang digunakan (useable respon rate) & 390 & $100 \%$ \\
\hline
\end{tabular}

Sumber: Data Penelitian,2019 
Tabel 1, menunjukkan bahwa kuesioner yang disebarkan sebanyak 390 eksemplar dengan pengembalian sebanyak 390 eksemplar atau tingkat pengembaliannya sebesar 100 persen, sehingga kuesioner yang disebarkan dapat digunakan seluruhnya yaitu sebanyak 390 eksemplar.

Data penelitian diperoleh dari kuesioner yang telah disebarkan berjumlah 390 dan diisi oleh wajib pajak orang pribadi non karyawan yang efektif di KPP Pratama Tabanan dengan rincian responden laki-laki berjumlah 236 orang dan responden perempuan berjumlah 154 orang. Responden yang berusia 20-29 tahun berjumlah 148 orang, berusia 30-39 tahun berjumlah 104 orang, berusia 4049 tahun berjumlah 102 orang, berumur 50-59 tahun berjumlah 32 orang, dan yang berusia $\geq 60$ tahun berjumlah 4 orang. Responden dengan tingkat pendidikan terakhirnya SMA berjumlah 150 orang, D3-S1 berjumlah 207 orang, Pascasarjana berjumlah 4 orang, dan selain SMA, D3-S1, dan pasca sarjana berjmlah 29 orang.

Instrumen-instrumen penelitian yang digunakan untuk mengukur variabel e-SPT, sanksi, sosialisasi, pengetahuan perpajakan, moralitas, dan kepatuhan wajib pajak dinyatakan valid. Hasil uji validitas instrumen penelitian menunjukkan bahwa seluruh indikator memiliki nilai Pearson Correlation yang lebih besar dari angka 0,30 sehingga seluruh indikator tersebut dikatakan telah memenuhi syarat validitas data. Semua variabel telah memenuhi syarat reliabilitas melalui uji reliabilitas, instrumen dikatakan reliable untuk mengukur variabel apabila memiliki nilai Cronbach Alpha lebih besar dari 0,60. Hasil uji reliabilitas instrumen pada penelitian ini menunjukkan bahwa kelima instrumen penelitian memiliki koefisien cronbach's alpha yang lebih besar dari 0,60 sehingga pernyataan pada kuesioner dapat dikatakan reliable dan dapat digunakan untuk melakukan penelitian.

Uji asumsi klasik yang dilakukan dalam penelitian ini meliputi uji normalitas, uji multikolinieritas, dan uji heteroskedastisitas, yang dapat dilihat pada Tabel 2, berikut.

Tabel 2. Hasil Uji Asumsi Klasik

\begin{tabular}{lllll}
\hline Variabel & Uji Normalitas & \multicolumn{2}{l}{ Uji Multikolinearitas } & Uji Heteroskedastisitas \\
\hline & $\begin{array}{l}\text { Kolmogorov- } \\
\text { Smirnov Z }\end{array}$ & Tolerance & VIF & Sig \\
& 1,315 & & & \\
E-SPT & & 0,532 & 1,881 & 0,677 \\
Sanksi & & 0,593 & 1,687 & 0,197 \\
Sosialisasi & & 0,541 & 1,847 & 0,059 \\
Pengetahuan & & 0,567 & 1,764 & 0,070 \\
perpajakan & & 0,695 & 1,439 & 0,279 \\
Moralitas & & &
\end{tabular}

Sumber : Data Penelitian, 2019

Uji normalitas dalam penelitian ini bertujuan untuk untuk menguji apakah variansi data berdistribusi normal atau tidak. Pengujian normalitas pada penelitian ini dilihat dari hasil nilai Kolmogorov-Smirnov. Berdasarkan hasil uji normalitas pada Tabel 2, dapat dilihat bahwa nilai Kolmogorov-Smirnov lebih besar dari 0,05 yaitu 1,315 sehingga nilai residual berdistribusi normal. 
Uji multikolinieritas dilakukan untuk menguji model regresi apakah ditemukan adanya korelasi antara variabel bebas. Hasil uji multikolinieritas pada Tabel 2, menunjukkan nilai tolerance variabel bebas lebih dari 0,10 dan VIF dari kurang dari 10. Hal tersebut menunjukkan bahwa model regresi bebas dari multikolinieritas.

Uji heteroskedastisitas bertujuan untuk mengetahui apakah dalam model regresi terjadi ketidaksamaan variance dari residual satu pengamatan ke pengamatan lain. Berdasarkan hasil uji heteroskedastisitas pada Tabel 2, dapat dilihat bahwa nilai signifikansi dari variabel bebas lebih besar dari $a=0,05$. Hal tersebut menunjukkan bahwa model regresi terbebas dari gejala heteroskedastisitas.

Statistik deskriptif bertujuan untuk memberikan informasi mengenai karakteristik variabel-variabel penelitian. Hasil uji analisis deskriptif dapat dilihat pada Tabel 3, berikut.

Tabel 3. Hasil Analisis Statistik Deskriptif

\begin{tabular}{|c|c|c|c|c|c|c|c|c|}
\hline Variabel & $\mathrm{N}$ & Min & $\operatorname{Max}$ & Mean & $\begin{array}{c}\text { Std. } \\
\text { Deviation }\end{array}$ & Range & Kategori & Nilai \\
\hline$\overline{\mathrm{E}-\mathrm{SPT}}$ & 390 & 22 & 50 & 42,55 & 4,917 & IV & $\mathrm{Ti}$ & $>38$ \\
\hline Sanksi & 390 & 12 & 25 & 21,52 & 2,189 & IV & Tinggi & $>19$, \\
\hline Sosialisasi & 390 & 14 & 30 & 24,31 & 3,789 & IV & Tinggi & $>23,6-26,8$ \\
\hline $\begin{array}{l}\text { Pengetahuan } \\
\text { Perpajakan }\end{array}$ & 390 & 11 & 25 & 21,01 & 2,585 & IV & ji & 2,2 \\
\hline Moralitas & 390 & 8 & 20 & 16,42 & 2,501 & IV & Tinggi & $>15,2-17,6$ \\
\hline $\begin{array}{l}\text { Kepatuhan Wajib } \\
\text { Pajak }\end{array}$ & 390 & 13 & 30 & 24,93 & 3,126 & IV & Tinggi & $>23,2-26,6$ \\
\hline
\end{tabular}

Sumber: Data Penelitian, 2019

Tabel 3, menunjukkan terdapat 390 amatan. Variabel e-SPT memiliki nilai minimum sebesar 22 dan nilai maksimum sebesar 50 dengan nilai rata-rata sebesar 42,55, berada pada range IV dengan kategori tinggi. Standar deviasi pada variabel e-SPT sebesar 4,917 lebih rendah dari nilai rata-rata yaitu sebesar 42,55 menunjukkan bahwa sebaran data variabel e-SPT sudah merata. Variabel sanksi memiliki nilai minimum sebesar 12 dan nilai maksimum sebesar 25 dengan nilai rata-rata sebesar 21,52, berada pada range IV dengan kategori tinggi. Variabel sanksi memiliki nilai standar deviasi sebesar 2,189 lebih rendah dari nilai ratarata yaitu sebesar 21,52 yang menunjukkan bahwa sebaran data terkait variabel sanksi sudah merata.

Variabel sosialisasi memiliki nilai minimum 14 dan nilai maksimum 30 dengan nilai rata-rata sebesar 24,31, berada pada range IV dengan kategori tinggi. Standar deviasi variabel sosialisasi sebesar 3,789 lebih rendah dibandingkan dengan nilai rata-rata yaitu sebesar 24,31 yang menunjukkan bahwa sebaran data terkait variabel sosialisasi sudah merata. Variabel pengetahuan perpajakan memiliki nilai minimum 11 dan nilai maksimum 25 dengan rata-rata sebesar 21,01, berada pada range IV dengan kategori tinggi. Variabel ini memiliki nilai standar deviasi sebesar 2,585 menunjukkan bahwa sebaran data terkait variabel pengetahuan perpajakan sudah merata. 
Variabel moralitas memiliki nilai minimum 8 dan nilai maksimum 20 dengan nilai rata-rata sebesar 16,42 , berada pada range IV dengan kategori tinggi. Standar deviasi variabel moralitas sebesar 2,501 lebih rendah dibandingkan dengan dengan nilai rata-rata yaitu 16,42 berarti sebaran data terkait moralitas sudah merata. Variabel kepatuhan wajib pajak memiliki nilai minimum 13 dan nilai maksimum 30, berada pada range IV dengan kategori tinggi. Nilai rata-rata dari variabel kepatuhan wajib pajak sebesar 24,93 . Nilai standar deviasi 3,126 lebih rendah dari nilai rata-rata yaitu sebesar 24,93 menunjukkan bahwa sebaran data terkait kepatuhan wajib pajak sudah merata.

Analisis regresi linier berganda dilakukan dengan menggunakan software SPSS dan diperoleh hasil yang ditunjukkan pada Tabel 4, berikut.

Tabel 4. Hasil Analisis Regresi Linier Berganda

\begin{tabular}{|c|c|c|c|c|c|}
\hline \multirow[b]{2}{*}{ Model } & \multicolumn{3}{|c|}{$\begin{array}{r}\text { Standardized } \\
\text { Unstandardized CoefficientsCoefficients }\end{array}$} & \multirow[b]{2}{*}{$\mathrm{T}$} & \multirow[b]{2}{*}{ Sig. } \\
\hline & $\mathrm{B}$ & Std. Error & Beta & & \\
\hline 1 (Constant) & $-0,639$ & 1,043 & & $-0,613$ & 0,540 \\
\hline E-SPT & 0,149 & 0,027 & 0,234 & 5,613 & 0,000 \\
\hline Sanksi & 0,324 & 0,056 & 0,227 & 5,736 & 0,000 \\
\hline Sosialisasi & 0,221 & 0,034 & 0,267 & 6,468 & 0,000 \\
\hline Pengetahuan & & & & & \\
\hline Perpajakan & 0,186 & 0,049 & 0,153 & 3,800 & 0,000 \\
\hline Moralitas & 0,184 & 0,046 & 0,147 & 4,037 & 0,000 \\
\hline
\end{tabular}

Sumber: Data penelitian, 2019

Berdasarkan hasil analisis regresi linier berganda pada Tabel 4, dapat dibuat persamaan regresi sebagai berikut:

$$
Y=-0,639+0,149 X_{1}+0,324 X_{2}+0,221 X_{3}+0,186 X_{4}+0,184 X_{5}+\varepsilon
$$

Interpretasi dari persamaan regresi diatas adalah nilai konstanta $-0,639$ $(0,540)$ berarti apabila nilai e-SPT $\left(X_{1}\right)$, sanksi $\left(X_{2}\right)$, sosialisasi $\left(X_{3}\right)$, pengetahuan perpajakan $\left(X_{4}\right)$, dan moralitas $\left(X_{5}\right)$ sama dengan nol, maka nilai kepatuhan wajib pajak (Y) tidak mengalami perubahan. Koefisien regresi e-SPT (X1) 0,149 $(0,000)$ berarti apabila $X_{1}$ meningkat 1 satuan, maka nilai $Y$ akan cenderung mengalami peningkatan, dengan asumsi variabel lain konstan. Koefisien regresi sanksi ( $\left.X_{2}\right)$ $0,324(0,000)$ berarti bila $X_{2}$ meningkat 1 satuan, maka $Y$ akan mengalami peningkatan, dengan asumsi variabel lain konstan. Koefisien regresi sosialisasi $0,222(0,000)$ berarti apabila nilai $X_{3}$ meningkat 1 satuan, maka nilai $Y$ mengalami peningkatan, dengan asumsi variabel lain konstan. Koefisien regresi pengetahuan perpajakan $\left(X_{4}\right) 0,186(0,000)$ berarti bila $X_{4}$ mengalami peningkatan 1 satuan, maka $Y$ akan mengalami peningkatan, dengan asumsi variabel lainnya konstan. Nilai koefisien regresi moralitas 0,184 $(0,000)$ memiliki arti apabila $\mathrm{X}_{5}$ meningkat 1 satuan, maka $Y$ akan cenderung meningkat, dengan asumsi variabel lainnya konstan.

Uji kelayakan model (Uji F) dilakukan untuk mengetahui apakah model penelitian yang digunakan untuk menguji pengaruh variabel bebas pada variabel terikat layak digunakan. Hasil uji $\mathrm{F}$ pada penelitian ini dapat dilihat pada Tabel 5, Berikut. 
Tabel 5. Hasil Uji Kelayakan Model (Uji F)

\begin{tabular}{lllllll}
\hline Model & Sum of Squares & $\mathrm{df}$ & Mean Square & $\mathrm{F}$ & Sig. \\
\hline 1 & Regression & 2452,128 & 5 & 490,426 & 139,602 & $0,000^{\mathrm{b}}$ \\
& Residual & 1349,002 & 384 & 3,513 & & \\
\multicolumn{2}{l}{ Total } & 3801,131 & 389 & & & \\
\hline
\end{tabular}

Sumber: Data Penelitian, 2019

Tabel 5, menunjukkan bahwa nilai signifikansi sebesar 0,000 yang artinya lebih kecil dari $a=0,05$. Hal ini menunjukkan bahwa secara simultan variabel bebas yaitu e-SPT, sanksi, sosialisasi, pengetahuan perpajakan, dan moralitas berpengaruh pada variabel terikat yaitu kepatuhan wajib pajak.

Uji koefisien determinasi $\left(\mathrm{R}^{2}\right)$ digunakan untuk mengukur seberapa jauh kemampuan variansi variabel independen dalam menerangkan variansi variabel dependen. Hasil uji koefisien determinasi dapat dilihat pada Tabel 6, berikut. Tabel 6. Hasil Uji Koefisien Determinasi $\left(\mathbf{R}^{2}\right)$

\begin{tabular}{lllll}
\hline Model & $\mathrm{R}$ & $\mathrm{R}$ Square & Adjusted R Square & Std. Error of the Estimate \\
\hline 1 & $0,803^{\mathrm{a}}$ & 0,645 & 0,640 & 1,874 \\
\hline
\end{tabular}

Sumber: Data Penelitian, 2019

Tabel 6, menunjukkan bahwa nilai Adjusted R-Square sebesar 0,640, hal ini berarti bahwa sebesar 64 persen variabel kepatuhan wajib pajak $(Y)$ dipengaruhi oleh variabel e-SPT $\left(X_{1}\right)$, sanksi $\left(X_{2}\right)$, sosialisasi $\left(X_{3}\right)$, pengetahuan perpajakan $\left(X_{4}\right)$, dan moralitas $\left(X_{5}\right)$. Sisanya sebesar 36 persen merupakan faktor lain di luar model yang dapat memengaruhi kepatuhan wajib pajak.

Uji hipotesis (uji t) digunakan untuk menunjukkan pengaruh semua variabel-variabel independen secara parsial pada variabel dependen. Hasil uji t dapat dilihat pada Tabel 7, berikut.

Tabel 7. Hasil Uji Hipotesis (Uji t)

\begin{tabular}{llll}
\hline Variabel & Koefisen Regresi & $\mathrm{t}_{\text {hitung }}$ & Sig. \\
\hline E-SPT & 0,149 & 5,613 & 0,000 \\
Sanksi & 0,324 & 5,736 & 0,000 \\
Sosialisasi & 0,221 & 6,468 & 0,000 \\
Pengetahuan Perpajakan & 0,186 & 3,800 & 0,000 \\
Moralitas & 0,184 & 4,037 & 0,000 \\
\hline
\end{tabular}

Sumber: Data Penelitian, 2019

Hasil uji hipotesis menunjukkan bahwa e-SPT memiliki nilai signifikansi 0,000 dengan koefisien regresi bernilai positif sebesar 0,149 . Nilai signifikansi 0,000 lebih kecil dari $\mathrm{a}=0,05$ ini berarti $\mathrm{H}_{1}$ diterima dengan begitu, variabel eSPT berpengaruh positif pada kepatuhan wajib pajak di KPP Pratama Tabanan. Sanksi memiliki nilai signifikansi 0,000 dengan koefisien regresi bernilai positif sebesar 0,324 , sehingga $\mathrm{H}_{2}$ diterima. Hal ini berarti sanksi berpengaruh positif pada kepatuhan wajib pajak di KPP Pratama Tabanan. Sosialisasi memiliki nilai signifikansi 0,000 dengan koefisien regresi bernilai positif sebesar 0,221, maka $\mathrm{H}_{3}$ diterima. Hal ini menunjukkan bahwa variabel sosialisasi berpengaruh positif pada kepatuhan wajib pajak di KPP Pratama Tabanan.

Pengetahuan perpajakan memiliki nilai signifikansi 0,000 dengan koefisien regresi bernilai positif sebesar 0,186. Hal ini berarti $\mathrm{H}_{4}$ diterima, 
sehingga variabel pengetahuan perpajakan berpengaruh positif pada kepatuhan wajib pajak di KPP Pratama Tabanan. Moralitas memiliki nilai signifikansi 0,000 dengan koefisien regresi bernilai positif sebesar 0,184, maka $\mathrm{H}_{5}$ diterima. Hal ini menunjukkan bahwa variabel moralitas berpengaruh positif pada kepatuhan wajib pajak di KPP Pratama Tabanan.

\section{SIMPULAN}

Berdasarkan hasil analisis dan pembahasan, dapat disimpulkan bahwa e-SPT berpengaruh positif pada kepatuhan wajib pajak. Sanksi berpengaruh positif pada kepatuhan wajib pajak. Sosialisasi berpengaruh positif pada kepatuhan wajib pajak. Pengetahun perpajakan perpajakan berpengaruh positif pada kepatuhan wajib pajak. Moralitas berpengaruh positif pada kepatuhan wajib pajak. Hasil penelitian ini dapat menambah wawasan mengenai faktor-faktor yang dapat mempengaruhi kepatuhan wajib pajak serta dapat digunakan sebagai bahan evaluasi bagi wajib pajak agar lebih meningkatkan kepatuhan dalam melaksanakan kewajiban perpajakannya.

Berdasarkan uraian data statistik dan hasil jawaban responden pada kuesioner, peneliti menyarankan kepada pihak regulator untuk lebih mempermudah sistem e-SPT agar semua wajib pajak bisa mengaplikasikan eSPT dengan baik dan lebih mempertegas sanksi bagi wajib pajak yang melanggar untuk meningkatkan kedisiplinan wajib pajak. Selain itu, KPP Pratama Tabanan diharapkan lebih meningkatkan sosialisasi pada wajib pajak mengenai penggunaan e-SPT agar lebih mudah dipahami. Sosialisasi secara langsung mengenai kewajiban membayar pajak juga perlu ditingkatkan oleh KPP Pratama Tabanan agar wajib pajak dapat berdiskusi secara langsung jika ada hal-hal yang kurang dipahami berkaitan dengan aturan perpajakan yang berlaku. Peneliti juga menyarankan untuk peneliti selanjutnya yang tertarik meneliti di bidang yang sama agar menambah variabel lain yang diduga dapat mempengaruhi kepatuhan wajib pajak.

\section{REFERENSI}

Adnyana, I. G. A., \& Jati, I. K. (2018). Pengaruh Sanksi Perpajakan, Penggunaan e-SPT, dan Kualitas Pelayanan Fiskus pada Kepatuhan Wajib Pajak Orang Pribadi. E-Jurnal Akuntansi. https://doi.org/10.24843/eja.2018.v25.i03.p19

Andreas, \& Savitri, E. (2015). The Effect of Tax Socialization, Tax Knowledge, Expediency of Tax ID Number and Service Quality on Taxpayers Compliance with Taxpayers Awareness as Mediating Variables. Procedia Social and Behavioral Sciences, 211(September), 163-169. https://doi.org/10.1016/j.sbspro.2015.11.024

Chirkos, A. Y. (2015). A Comparative Study of Compliant and Non- Compliant Individual Taxpayers in Ethiopia evidence from Amhara region. Journal of Economics and Sustainable Development, 5(24), 10-19.

Damajanti, A., \& Abdul Karim, S. Ms. A. (2017). Effect of Tax Knowledge on Individual Taxpayers Compliance. Economic \& Business Solutions Journal, 1(1), 1-19.

Dewi Kusuma Wardani dan Erma Wati. (2018). Wajib Pajak Dengan Pengetahuan Perpajakan Sebagai Variabel Intervening (Studi Pada Wajib Pajak Orang Pribadi di 
KPP Pratama Kebumen) The Effect Of Tax Socialization On Taxpayer Compliance With. VII.

Dewi, N. L. P. ., \& Noviari, N. (2017). Devi Dan Noviari, Ubi. Pengaruh Ukuran Perusahaan, Leverage, Profitabilitas Dan Corporate Social Responsibility Terhadap Penghindaran Pajak (Tax Avoidance), 21, 830-859.

Direktorat Jenderal Pajak. (2018). Laporan Kinerja Direktorat Jenderal Pajak 2018. Faris Naufal, M., \& Setiawan, P. E. (2018). Pengaruh Sosialisasi Perpajakan, Pemahaman Prosedur Perpajakan, Umur, Jenis Pekerjaan Terhadap Kepatuhan Wajib Pajak Orang Pribadi. E-Jurnal Akuntansi, 25, 241. https://doi.org/10.24843/eja.2018.v25.i01.p10

Fauziah, U. (2016). Pengaruh Sistem Administrasi Perpajakan Modern, Sosialisasi Perpajakan dan Kewajiban Moral Terhadap Kepatuhan Wajib Pajak (Studi Empiris pada Wajib Pajak Orang Pribadi di KPP Pratama Sleman). Jurnal Akuntansi Fakultas Ekonomi Dan Bisnis Universitas Muhamadiyah Yogyakarta, $28,800-827$.

Fernando, \& Arisman, A. (2017). Pengaruh Sosialisasi Perpajakan , Pengetahuan Perpajakan, dan Sanksi Perpajakan Terhadap Kepatuhan Wajib Pajak Orang Pribadi ( Studi Empiris Pada Wajib Pajak Orang Pribadi Yang Terdaftar Di KPP Pratama Palembang Seberang Ulu ). MDP Business Scholl, $1(\mathrm{x}), 1-14$.

Handayani, M., \& Noviari, N. (2016). Pengaruh Persepsi Manajemen Atas Keunggulan Penerapan E-Billing Dan E-SPT Pajak Pertambahan Nilai Pada Kepatuhan Perpajakan. E-Jurnal Akuntansi, 15(2), 1007-1-1028.

Handayani, O., \& Woro Damayanti, T. (2018). Determinants of Individual Taxpayers Compliance in Indonesia: A Meta-Analysis. The Indonesian Journal of Accounting Research, 21(1), 1-22. https://doi.org/10.33312/ijar.332

Hartana, I. M. G., \& Merkusiwati, N. K. L. A. (2018). Sosialisasi Perpajakan Memoderasi Pengaruh Kesadaran Wajib Pajak dan Sanksi Perpajakan pada Kepatuhan Wajib Pajak. E-Jurnal Akuntansi. https://doi.org/10.24843/eja.2018.v25.i02.p26

Heenkenda, S. (2016). Readiness to retirement planning of estate sector employees in Sri Lanka Readiness to Retirement Planning of Estate Sector Employees in Sri Lanka. MPRA Munich Personal RePEc Archive. https://doi.org/10.1227/01.NEU.0000349921.14519.2A

Juliantara, I. G. R., \& Setiawan, P. E. (2017). Kemudahan Pengisian SPT, Pengetahuan Perpajakan, Kualitas Pelayanan Pada Kepatuhan WPOP di KPP Pratama Denpasar Timur. E- Jurnal Akuntansi Universitas Udayana.

Kesumasari, N. K. I., \& Suardana, K. A. (2018). Pengaruh Pengetahuan Perpajakan, Kesadaran dan Pengetahuan Tax Amnesty Pada Kepatuhan WPOP di KPP Pratama Gianyar. E-Jurnal Akuntansi, 22, 1503. https://doi.org/10.24843/eja.2018.v22.i02.p25

Kusumafanto, H. F., \& Fatchan Achyani. (2018). Pengaruh Kualitas Pelayanan, Sanksi Perpajakan, Biaya Kepatuhan Pajak, Penerapan E-Filing Dan Pengetahuan Perpajakan Terhadap Kepatuhan Wajib Pajak Orang Pribadi (Studi pada Wajib Pajak Orang Pribadi di KPP Pratama Surakarta). Jurnal Akuntansi Fakultas Ekonomi Dan Bisnis Universitas Mohamadiyah Surakarta, 24(2), 1590-1607. https://doi.org/10.1051/matecconf/201712107005 
Kusumayanthi, L. O., \& Suprasto, H. B. (2019). Pengaruh Penerapan E-Filling, Sosialisasi Perpajakan, Kinerja Account Representative, dan Sanksi Pajak terhadap Tingkat Kepatuhan WPOP. E-Jurnal Akuntansi, 28, 491. https://doi.org/10.24843/eja.2019.v28.i01.p19

Mahangila, D. N. (2017). The Impact of Tax Compliance Costs on Tax Compliance Behavoiur. Journal of Tax Administration, 3(1), 57-81. https://doi.org/10.1017/CBO9781107415324.004

Manual, V., \& Zhi Xin, A. (2016). Impact of Tax Knowledge, Tax Compliance Cost, Tax Deterrent Tax Measures towards Tax Compliance Behavior: A survey on Self-Employed Taxpayers in West Malaysia. Electronic Journal of Business and Management, 1(1), 56-70.

Marjan, R. M. (2014). Pengaruh Kesadaran Wajib Pajak, Pelayanan Fiskus, dan Sanksi Pajak terhadap Tingkat Kepatuhan Formal Wajib Pajak (Studi di Kantor Pelayanan Pajak Pratama Makassar Selatan). Jurnal Akuntansi Fakultas Ekonomi Dan Bisnis Universitas Hasanuddin, 5(1), 43-54. https://doi.org/10.1017/CBO9781107415324.004

Markumah, U., Triyono, \& Sasongko, N. (2019). Pengaruh Ketegasan Sanksi Pajak,Pengetahuan Fiskus, Reformasi Perpajakan terhadap Kepatuhan Wajib Pajak(Studi Empiris Pada Wajib Pajak Badan di KPP Pratama Surakarta). Urecol, 191-198.

Mitha Pratiwi, N. P., \& Merkusiwati, N. K. L. A. (2019). Pengaruh Kualitas Pelayanan, Kewajiban Moral, Sanksi Pajak dan Tapping Box pada Kepatuhan Wajib Pajak Hotel. E-Jurnal Akuntansi, 26(32), 1357. https://doi.org/10.24843/eja.2019.v26.i02.p19

Newcomb, T., \& Heider, F. (1958). The Psychology of Interpersonal Relations. American Sociological Review. https://doi.org/10.2307/2089062

Parwati, N. M. S., Tenripada, \& Zahra, F. (2017). The analysis of factors affecting the use of e-filing for individual taxpayers. International Conference on Accounting, Business \& Economics, 2(October).

Pranata, F. M., \& Puspa, D. F. (2014). Pengaruh Karakter Eksekutif Dan Corporate. E-Jurnal Bung Hatta Vol. 4 No. 1 (2014).

Pratami, L. P. K. A. W., Sulindawati, N. L. G. E., \& Wahyuni, M. A. (2017). Pengaruh penerapan e-system perpajakan terhadap tingkat kepatuhan wajib pajak orang pribadi dalam membayar pajak pada kantor pelayanan pajak (kpp) pratama singaraja. E-Jurnal Akuntansi. https://doi.org/10.24843/eja.2018.v22.i03.p09

Priambodo, P. (2018). The Influence of Understanding Tax Regulation, Sanction Taxation, Awareness Tax Payers to Compliance Tax Payers of Private Person at Tax Services Office Pratama. Journal of Accounting and Business Education, 5(1), 2450-2462. https://doi.org/10.1017/CBO9781107415324.004

Purwadi, M. O. D. (2019). Pengaruh Religiusitas, Pelayanan Fiskus dan Sanksi Pajak pada Kepatuhan Wajib Pajak Orang Pribadi di Kantor Pelayanan Pajak Pratama Badung Selatan. E-Jurnal Akuntansi Universitas Udayana, 27(9), 1689-1699. https://doi.org/10.1017/CBO9781107415324.004

Redae, R. B., \& Sekhon, P. S. (2016). Taxpayers' Knowledge and Tax Compliance Behavior in Ethiopia: A Study of Tigray State. International Journal of Management and Commerce Innovations, 3(2), 1090-1102. Retrieved from 
www.researchpublish.com

Robbins, R. B. \& Judge, T. (2013). Organizational Behavior. 15th edition. New Jersey: Pearson Education Inc (15th editi). New Jersey: Pearson Education Inc.

Savitri, E., \& Musfialdy. (2016). The Effect of Taxpayer Awareness, Tax Socialization, Tax Penalties, Compliance Cost at Taxpayer Compliance with Service Quality as Mediating Variable. Procedia - Social and Behavioral Sciences, 219, 682-687. https://doi.org/10.1016/j.sbspro.2016.05.051

Setyani, A. Y. (2018). Pengaruh Kebijakan Dividen, Kebijakan Hutang Dan Profitabilitas Terhadap Nilai Perusahaan Manufaktur. Jurnal Fakultas Bisnis Universitas Kristen Duta Wacana, 18(2), 181. https://doi.org/10.34209/equ.v18i2.467

Sondakh, J. J. (2017). Behavioral intention to use e-tax service system: An application of technology acceptance model. European Research Studies Journal, 20(2), 48-64.

Sugiyono. (2016). Metode Penelitian Bisnis (Pendekatan Kuantitatif, Kualitatif, dan $R \mathcal{E D}$ ). Bandung: Alfabeta.

Wanzel, K. R., Ward, M., \& Reznick, R. K. (2002). Teaching the surgical craft: From selection to certification. Current Problems in Surgery. https://doi.org/10.1067/mog.2002.123481

Wijayanti, L. P. C., \& Sukartha, I. M. (2018). Pengaruh Tarif Progresif, Kualitas Pelayanan, Sosialisasi Perpajakan dan Pengetahuan Perpajakan Pada Kepatuhan Wajib Pajak. E-Jurnal Akuntansi. https://doi.org/10.24843/eja.2018.v25.i03.p15

Yulitasari, A. A. I., \& Suprasto, H. B. (2017). Pengaruh Tanggung Jawab Moral, Sanksi Perpajakan dan Penerapan Sistem E-Filing Pada Kepatuhan Pelaporan Wajib Pajak. E-Jurnal Akuntansi Universitas Udayana, 20(2), 13601389. https://doi.org/10.1051/matecconf/201712107005 